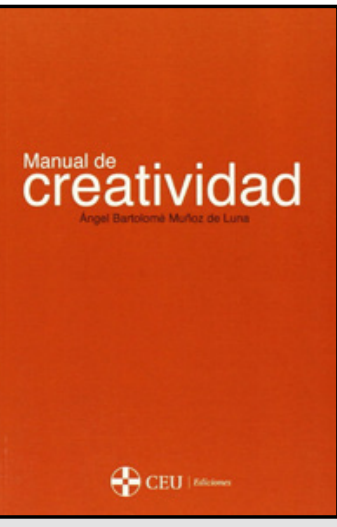

Manual de creatividad

Ángel Bartolomé Muñoz de Luna

Fundación Universitaria San Pablo CEU,

Madrid, 2015

\title{
La democratización de la creatividad
}

A

través de esta obra, editada por CEU Ediciones, el Profesor Doctor Ángel Bartolomé Muñoz de Luna (Universidad CEU San Pablo) ofrece una visión global y práctica de un objeto de estudio tan complejo y multidisciplinar como es la creatividad. La oportunidad de este libro responde a la propia necesidad que las sociedades en crisis manifiestan por apostar por nuevas creaciones en los muy diversos campos que condicionan nuestras vidas. Publicado en 2015, el texto hace una excelente revisión bibliográfica de un tema que ha motivado múltiples investigaciones, aunque siga encerrando multitud de secretos. El libro ofrece una perspectiva muy completa sobre la creatividad, haciendo una aproximación a las diferentes líneas que han tratado dicho objeto de estudio y ofreciendo como resultado una magnífica guía para comprender las problemáticas que entraña y sus diversas posibilidades de análisis y desarrollo.

Las 126 páginas del libro se dividen en 6 interesantes capítulos. El primero de ellos se focaliza en el concepto de creatividad, sus orígenes, sus dificultades y las diversas acepciones aportadas desde diferentes aproximaciones científicas. En este capítulo, se destaca la complejidad de la creatividad y su conceptualización que, "sujeta al dinamismo de la propia historia del hombre", requiere una "constante revisión y reformulación" (pág. 27). El segundo capítulo sintetiza el controvertido debate generado en este ámbito científico entre creatividad e inteligencia, vinculándolo a la teoría de las inteligencias múltiples de Howard Gardner. A lo largo del tercer capítulo se aborda el 


\section{2 | Carmen Llorente Barroso}

\section{RESEÑAS Y REVISIONES}

estudio de la persona creativa, sus características, los bloqueos que limitan el desarrollo de su creatividad y los tipos de pensamiento asociados a la personalidad creadora. El cuarto capítulo es uno de los más útiles, ya que aborda la aproximación a la creatividad a través del análisis del proceso creativo. De este modo, hace un recorrido por los modelos clásicos y cognitivos, refiriéndose a los autores más destacados dentro de cada propuesta. Este capítulo continúa desgranando los principios que rigen el hallazgo de nuevas ideas para culminar con la explicación de seis de las técnicas de creatividad más productivas: el brainstorming, la analogía, los seis sombreros para pensar, las relaciones forzadas, las matrices combinatorias y el SCAMPER. El capítulo quinto está dedicado al estudio de las características del producto creativo, entendido como la prueba más tangible de la creatividad. El trabajo se clausura con el capítulo dedicado a la bibliografía, con un compendio tan completo como útil. A lo largo de toda la obra, el texto se apoya en los autores que se encumbran como los referentes más representativos de la creatividad: Joy P. Guilford, Edward de Bono o Howard Gardner.

El libro se caracteriza por el rigor científico-académico exigido a este tipo de obras, pero también por su practicidad y fácil comprensión. Además del interés investigador y documental del trabajo, destaca su carácter pedagógico, lo que enmarca el libro como una aportación científico-académica imprescindible. Investigadores, profesores y estudiantes del extenso campo de la creatividad, agradecerán esta propuesta, caracterizada por su rigor, su carácter divulgativo, la buena expresión de su redacción, su claridad, su valor práctico y su dimensión didáctica. Esta obra, resultado de la brillante trayectoria de su autor, abre también las puertas a la reflexión, especialmente, en la parte en la que se abordan las complejidades de la creatividad y la relación entre la misma y la inteligencia.

La propuesta de Ángel Bartolomé Muñoz de Luna enfatiza que “la creatividad, aunque sigue guardando secretos a los investigadores, se ha democratizado, para hacerse más accesible a todos". En definitiva, el texto supone una valiosa contribución, particularmente, si se tienen en cuenta las necesidades actuales por el desarrollo de la creatividad para poder afrontar con éxito los nuevos retos.

Carmen Llorente Barroso Universidad CEU San Pablo 